\title{
Decomposition Analysis of Carbon Emission of Industrial Energy Consumption in Guangzhou from 2003 to 2016
}

\author{
Bo Chen ${ }^{3,4,}$, Zhihai Gong ${ }^{1,2,4, ~ b}$, Junsong Jia ${ }^{1,2, *}$ \\ ${ }^{1}$ Key Laboratory of Poyang Lake Wetland and Watershed Research, Ministry of Education, Jiangxi \\ Normal University, Nanchang, Jiangxi, 330022, China \\ ${ }^{2}$ School of Geography and Environment, Jiangxi Normal University, Nanchang, Jiangxi, 330022, \\ China \\ ${ }^{3}$ College of Physics and Communication Electronics, Jiangxi Normal University, Nanchang, Jiangxi, \\ 330022, China \\ ${ }^{4}$ School of Graduate, Jiangxi Normal University, Nanchang, Jiangxi, 330022, China \\ achenbo170122@foxmail.com, bogongzhihai0228@163.com
}

Keywords: energy consumption; carbon emission; industry; LMDI; Guangzhou.

\begin{abstract}
Based on the characteristics of energy use and economic output of light industry and heavy industry, the carbon emission of main energy consumption in Guangzhou's industry from 2003-2016 is analyzed by the Logarithmic Mean Divisia Index method (LMDI). The results show that the economic scale effect and industrial structure effect were the leading factors for the increase of carbon emission but both them were getting weaker. On the other hand, the energy intensity effect is the main factor in the carbon emission suppression of Guangzhou's industry, which was also getting weaker. What's more, the heavy industry plays the most important role both in carbon emission and emission suppression. Therefore, some suggestions on the future control of carbon emission in Guangzhou's industrial development are put forward in the end.
\end{abstract}

\section{Introduction}

The main contributor to the increase in global greenhouse gas emissions is fossil energy consumption, and the resulting $\mathrm{CO} 2$ emission dominates the global carbon emissions [1]. Guangzhou is the third largest city in China. Therefore, it is significant to study the changing characteristics of carbon emissions from energy consumption in Guangzhou, and analyze the mechanism of its main influencing factors.

Currently, the decomposition methods commonly used in energy consumption and carbon emission decomposition analysis include structural decomposition analysis (SDA) and index decomposition analysis (IDA). Among them, the SDA method can make a more detailed analysis of various influencing factors such as the final demand of the industrial sector and international trade based on the input-output table and the consumption coefficient matrix. The main methods include the input-output method and the bipolar decomposition method [2-3]; The IDA method makes it easier to conduct time series analysis and cross-border comparison by using the sum data of industrial departments. The main methods include Laspeyres index decomposition and Divisia index 
decomposition. [4-5]

In this paper, we consider the economic output scale, industrial structure, energy intensity and energy structure, and establish a factor decomposition model of carbon emissions from energy consumption. Then from the aspects of light industry and heavy industry, this paper makes an empirical analysis on the carbon emission of major industrial energy consumption in Guangzhou from 2003 to 2016, and tries hard to reflect the mechanism of each factor more comprehensively. On this basis, we propose policy recommendations for energy saving and emission reduction in Guangzhou's industry.

\section{Data and Methods}

\subsection{Data Sources}

The data used in this paper are derived from the industrial energy consumption and output value in Guangzhou Statistical Yearbook from 2003 to 2016. The carbon emission coefficients of coal, fuel oil, gasoline and diesel fuel are 1.83, 3.1866, 2.9251, and 3.1022, respectively, according to data from the Energy Research Institute of the National Development and Reform Commission (NDRC).

\subsection{Model establishment}

We use Logarithmic Mean Divisia Index method and use the model adopted in Sun J.W.'s[6] study to research the decomposition of Guangzhou's industrial energy consumption. The modified factorization model is as follows:

$$
\mathrm{C}=\sum_{\mathrm{i}=1}^{3} \mathrm{Ci}=\sum_{\mathrm{i}=1}^{3}\left(\mathrm{Y} \times \frac{\mathrm{Y}_{\mathrm{i}}}{\mathrm{Y}} \times \frac{\mathrm{E}_{\mathrm{i}}}{\mathrm{Y}_{\mathrm{i}}} \times \frac{\mathrm{C}_{\mathrm{i}}}{\mathrm{E}_{\mathrm{i}}}\right)
$$

In this formula, $\mathrm{C}$ denotes the carbon emission, $\mathrm{Y}$ denotes the gross domestic product (GDP), and $\mathrm{E}$ denotes the energy consumption; Lower case i distinguish the industries, then $\mathrm{Ei}, \mathrm{Yi}$ and $\mathrm{Ci}$ represent the energy consumption, GDP and $\mathrm{CO}_{2}$ emissions of the i-th industry respectively. And here defines:

$$
\mathrm{S}_{\mathrm{i}}=\frac{\mathrm{Y}_{\mathrm{i}}}{\mathrm{Y}}, \mathrm{I}_{\mathrm{i}}=\frac{\mathrm{E}_{\mathrm{i}}}{\mathrm{Y}_{\mathrm{i}}}, \mathrm{F}=\frac{\mathrm{C}_{\mathrm{i}}}{\mathrm{E}_{\mathrm{i}}}
$$

Then the energy consumption $\mathrm{CO}_{2}$ emission model expression is:

$$
\mathrm{C}=\sum_{\mathrm{i}=1}^{3}\left(\mathrm{Y} \times \mathrm{S}_{\mathrm{i}} \times \mathrm{I}_{\mathrm{i}} \times \mathrm{F}_{\mathrm{i}}\right)
$$

Formula (3) is decomposed according to additive decomposition method of the LMDI model, The differences on $\mathrm{CO}_{2}$ emissions from year 0 (base year) to year t (target year) is called the total effect, which can be expressed by $\Delta$ Ctot. The total effect can be decomposed into economic scale effect, industrial structure effect, energy intensity effect and industrial emission coefficient effect. Then

$$
\Delta \mathrm{C}_{\text {tot }}=\mathrm{C}_{\mathrm{T}}-\mathrm{C}_{0}=\Delta \mathrm{C}_{\mathrm{Y}}+\Delta \mathrm{C}_{\mathrm{S}}+\Delta \mathrm{C}_{\mathrm{I}}+\Delta \mathrm{C}_{\mathrm{F}}
$$

While the $\Delta \mathrm{C}_{\mathrm{x}}$ can be expressed as the follows:

$$
\Delta \mathrm{C}_{\mathrm{x}}=\sum_{\mathrm{i}=1}^{3} \frac{\mathrm{C}_{\mathrm{i}}^{\mathrm{T}}-\mathrm{C}_{\mathrm{i}}^{0}}{\ln \mathrm{C}_{\mathrm{i}}^{\mathrm{T}}-\ln \mathrm{C}_{\mathrm{i}}^{0}} \times \ln \frac{\mathrm{x}_{\mathrm{i}}^{\mathrm{T}}}{\mathrm{x}_{\mathrm{i}}^{0}}
$$

Among them, $\mathrm{X}$ represents the economic scale effect, the industrial structure effect, the energy intensity effect, and industrial emission coefficient effect, respectively.

After decomposition, if the additive decomposition values are greater than zero, it means that the effect leads to an increase in $\mathrm{CO}_{2}$ emissions, which in turn means that the effect leads to a reduction in 
$\mathrm{CO}_{2}$ emissions.

\section{Analysis of Guangzhou's Industrial Energy Consumption in Current Situation}

\subsection{Industrial output and energy consumption in current situation}

Guangzhou is one of the poorest areas whose energy resources are scare in China; its crude oil and natural gas are completely dependent on outsourcing, which cause its energy self-sufficiency rate very low. In 2016, Guangzhou's industrial output reached 2112.5 billion CNY which is an increase of about 3.7 times over 2004, with an average annual growth rate of $12.10 \%$. On the contrary, the total energy consumption of Guangzhou's industry is to rise first during 2004-2011 and then fall during 2011-2016 in total. Among them, it also slightly rises during 2014-2016. (see Fig.1a) The total energy consumption in Guangzhou's industry in 2016 was 23.81 million tons of standard coal, only an increase of 1.1 times over 2004. It shows that Guangzhou's energy efficiency has improved markedly since 2010. This may be due to the holding of the Guangzhou Asian Games which urges local governments to govern high-energy-consuming and high-emission enterprises.

\subsection{Energy consumption in light and heavy industries}

If the industry is divided into light industry and heavy industry, we find that the growth rate of heavy industry from 2004-2016 is much higher than that of light industry.(see Fig.1b) At the same time, Guangzhou's total industrial energy consumption growth is very small. From this we can speculate that increased energy efficiency in Guangzhou's heavy industry has made a significant contribution to reducing industrial energy consumption.

\subsection{Change in energy consumption intensity}

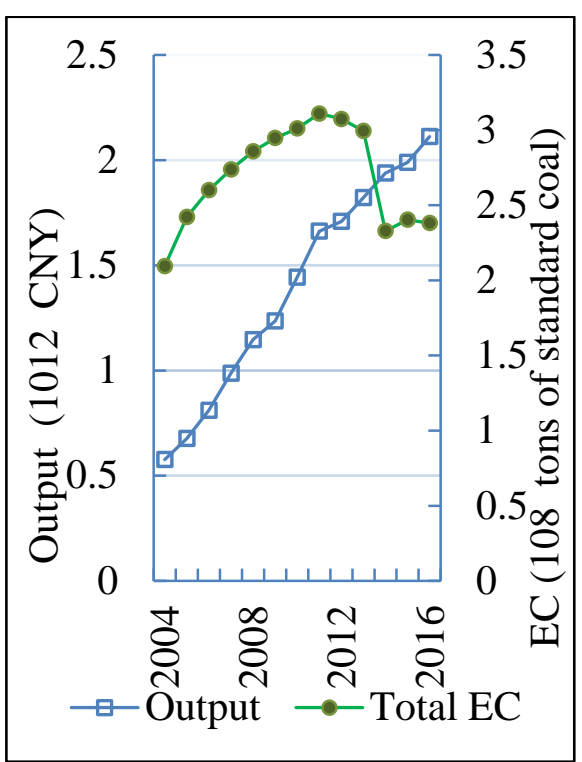

$\mathrm{a}$
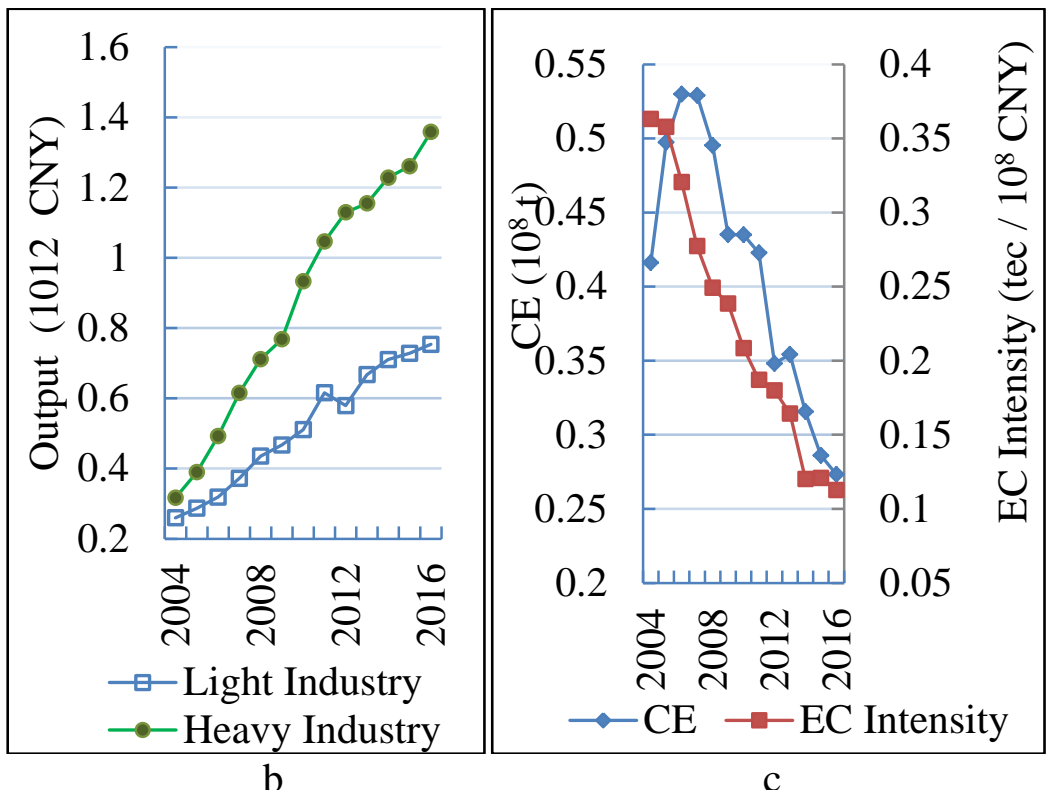

Fig.1 Output, Energy Consumption (EC)(a), Light and Heavy industry’s Output(b) and Carbon Emission (CE), EC Intensity(c) of Guangzhou's industry from 2004-2016

Energy consumption intensity is the ratio of energy use to economic output. As the energy consumption per unit of GDP, energy consumption intensity is a very important indicator to reflect a region's industrial structure, technical level and management level and comprehensive utilization 
efficiency of energy. It also embodies regional sustainable development capacity. From 2004 to 2016, although energy consumption in Guangzhou's industry was to rise first and then fall, the intensity of energy consumption was declining continuously, with an annual average decline rate of 9.2\%.(see Fig.1c) The main reason is Guangzhou's industrial restructuring and the application and promotion of high-tech.

\section{Decomposition results and analyses}

The main-energy-consumption carbon emission of Guangzhou's industry increased from 2004 to 2006, then began to decline from 2007 to 2016. The shape likes an 'inverted U', and the "inverted U”' right wing is longer and lower than left wing. On the whole the carbon emission of Guangzhou's industry shows a declining trend. (see Fig.1c)

As is shown in decomposition results from Fig.2, the energy intensity effect greatly reduced the carbon emission, so the energy intensity effect was the slowing factor of carbon emission growth. But the economic scale effect was positively related to the growth of carbon emission, so economic growth was a contributing factor to the growth of carbon emission. The details are analyzed in follows.

\subsection{Economic scale effect}

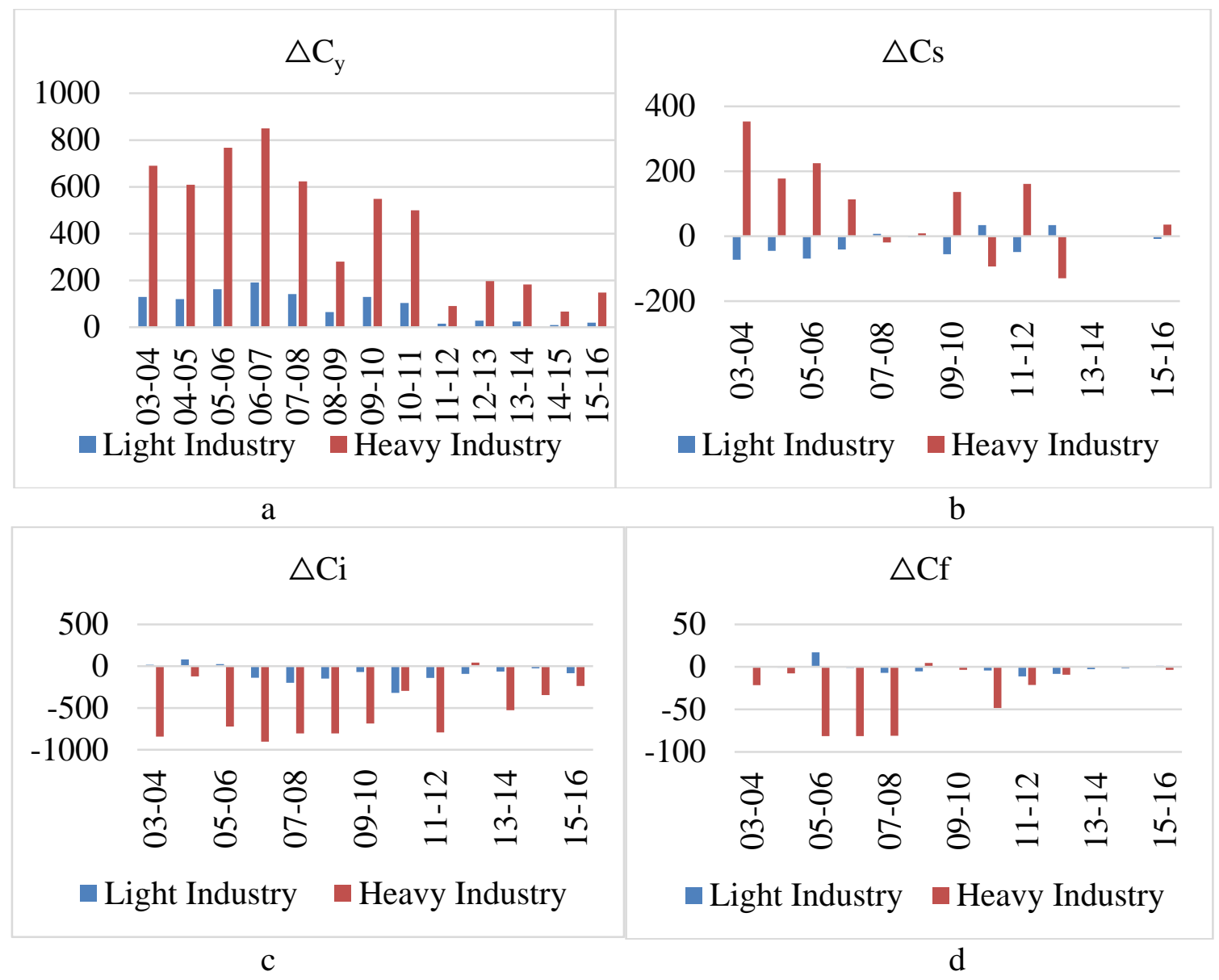

Fig.2 Four Effects of light and heavy Industries in Guangzhou from 2003 to $2016 . \Delta \mathrm{C}_{\mathrm{y}}, \Delta \mathrm{Cs}, \Delta \mathrm{Ci}$, $\Delta$ Cf represent economic scale effect, industrial structure effect, energy intensity effect, and industrial emission coefficient effect, respectively, 03-04 refers to year 2003-2004. Unit: $10^{4}$ tonnes(t). ) 
First of all, the economic scale effect had a positive impact on both light and heavy industry's carbon emission from 2003-2016. And the contribution of carbon emission on total economic scale effect was particularly larger than any other effects. Besides, the trend of this contribution is consistent with the trend of carbon emission in Guangzhou, indicating that the economic scale effect was an important source of the 'inverted U' shape on carbon emission. What's more, the contribution of heavy industry is greatly larger than which of light industry, it shows that the heavy industry is the main factor of Guangzhou's industrial energy-consumption carbon emission. Last but not least, the economic scale effect was getting weaker in the contribution of carbon emission of Guangzhou during 2003-2016.(see Fig.2a)

\subsection{Industrial structure effect}

The industrial structure effect had a main positive impact of carbon emission suppression in the light industry, but its trend is opposite with that in carbon emission, indicating that the 'inverted U' shape of Guangzhou's carbon emission is unrelated to the industrial restructuring in light industry. In most year, although the industrial structure effect had a negative impact of carbon emission suppression in the heavy industry, the contribution shows a declining trend. It indicates that the overall industrial structure of heavy industry in Guangzhou is constantly being optimized. (see Fig.2b)

\subsection{Energy intensity effect}

As for the energy intensity effect, it reduced both the light and heavy industry's carbon emission during 2003-2016, it proved that the energy intensity effect is a factor to Guangzhou's industrial carbon emission. Further, the total contribution of $\mathrm{CO}_{2}$ emission suppression in the heavy industry were particularly larger than that in light industry, indicating that the decrease of carbon emission was mainly due to the improvement of energy efficiency of the heavy industry. At the same time, the trend of the contribution on carbon emission suppression is opposite with that on carbon emission, indicating that the energy intensity effect was getting weaker. (see Fig.2c)

\subsection{Industrial emission coefficient effect}

The industrial emission coefficient effect actually reflects the energy structure of an industry. In recent years, Guangzhou vigorously eliminated the backward production capacity, and enhanced the development of energy-saving industries, thus the proportion of clean energy use was greatly improved. In the industrial emission coefficient effect, the heavy industry also occupies a major part of the carbon footprint reduction during 2005-2008 and 2010-2013, which means that the role of energy structure optimization in heavy industry in reducing carbon emission also cannot be ignored. Although this result exists, its affection on the 'inverted U' shape was not so distinguished, because its trend is not entirely regular. (see Fig.2d)

In total, the economic scale effect and industrial structure effect is the main factor in the carbon footprint of Guangzhou's industry, but both them were getting weaker, during 2003-2016. The heavy industry contributed larger than light industry in the carbon emission. In the other hand, the energy intensity effect is the main factor in the carbon emission suppression of Guangzhou's industry, it was also getting weaker. The industrial emission coefficient effect is another factor in the carbon emission suppression of Guangzhou's industry, but it's not as distinguished as the energy intensity effect. The heavy industry also contributed larger than light industry in the carbon emission suppression. 


\section{Conclusions}

According to the comprehensive analysis of energy consumption and economic growth trends, we can also reveal a deeper reason that Guangzhou's industrial development has entered a high level stage, with the initial realization of the carbon emission reduction through the development of energy-saving industries. The corresponding energy consumption is tending to increase again from 2014, while the carbon emission base is still large, although the low-carbon industry share rose rapidly. In view of this, Guangzhou should continue to phase out the development model of high energy-consuming industrial economics especially heavy industries, and transform them into the economic development model which is diversified, environmental protection, energy saving, high value-added. Only if it makes the policy of low-carbon economy, and gradually gets rid of heavy chemical industry, at the same time improve the energy structure and use more new energies, can Guangzhou's economy achieve the sustainable development.

\section{Acknowledgements}

We are grateful for the financial support provided by Chinese National Science Foundation (71473113, 31360120, 51408584) and Natural Science Foundation of Jiangxi (20151BAB203040). Corresponding author Junsong Jia can be contacted by (86)18607918843 or jiaaniu@126.com.

\section{References}

[1] IPCC. IPCC Fourth Assessment Report [EB/OL]. http://www.ipcc.ch/ipccreports/ar4-wg3.htm, 2009-05-17.

[2] Hoekstra R, van der Bergh J C J M. Comparing structural and index decomposition analysis [J]. Energy Economics, 2003, 25 (1):39 64.

[3] LIANG Jinshe, ZHENG Wei, CAI Jianming. The decomposition of energy consumption growth in China: Based on input-output model [J]. Journal of Natural Resources, 2007, 22 (6): 853 864.

[4] GAO Zhenyu, Wang Yi. The decomposition analysis in change of productive energy consumption of China [J]. Statistical Research, 2007, 24 (3): 52 57.

[5] LI Guozhang, Wang Shuang. Regional factor decompositions in china's energy intensity change: Base on LMDI technique [J]. Journal of Finance and Economics, 2008, 34 (8): 52 62.

[6] Sun. J. W. Changes in energy consumption and energy intensity: a complete decomposition model. Energy Economics, 1998.

[7] Information on http:// http://www.gzstats.gov.cn 